\title{
Adaptaçáo transcultural da bateria DLOTCA-G (Dynamic Lowenstein Occupational Therapy Cognitive Assessment - for Geriatric Population) para a língua portuguesa
}

\author{
Marcia Maria Pires Camargo Novelli ${ }^{a, b}$, Nataly Cristina Fachinetti Marques ${ }^{b}$, \\ Mariana Matteuci ${ }^{b}$, Renata Souza Mendes ${ }^{b}$, Amanda Sardinha de Medeiros ${ }^{b}$, Juliana Kuga ${ }^{b}$, \\ Amanda Fabrício Machado ${ }^{b}$, Lúcia da Rocha Uchôa-Figueiredo ${ }^{a}$, Noomi Katz \\ aUniversidade Federal de São Paulo - UNIFESP, Campus Baixada Santista, Santos, SP, Brasil.

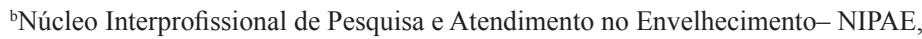 \\ Universidade Federal de São Paulo - UNIFESP, Campus Baixada Santista, Santos, SP, Brasil.

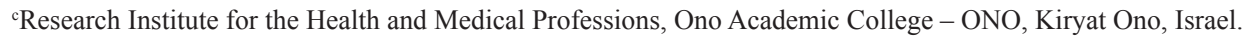

\begin{abstract}
Resumo: Introdução: A bateria DLOTCA-G (Dynamic Loewenstein Occupational Therapy Cognitive Assessment-for Geriatric Population) é uma avaliação dinâmica dos componentes cognitivos de idosos em oito áreas: orientação, percepção visual e espacial, práxis, construção visomotora, operações de pensamento, memória e consciência. Objetivo: Adaptar transculturalmente a bateria DLOTCA-G para o português do Brasil. Métodos: O processo de adaptação transcultural seguiu a metodologia de tradução, retrotradução, avaliação das equivalências semânticas, idiomáticas, conceituais e culturais, seguidas por pré-teste. Resultados: Na etapa de tradução foram feitas inclusões e exclusões de palavras visando ao entendimento do conteúdo em português. Na avaliação das equivalências semânticas e idiomáticas dos 355 itens avaliados, 23 itens apresentaram discordância. Nas equivalências conceituais, dos 37 itens analisados nenhum apresentou discordância e, nas equivalências culturais, dos 37 itens avaliados dois itens apresentaram discordância. Os itens discordantes foram modificados a partir das sugestões dos juízes, o que produziu a terceira versão traduzida e adaptada da bateria que foi aplicada (pré-teste) em uma amostra de 10 idosos de uma comunidade. Nessa fase não foram identificadas dificuldades na sua aplicação, tanto em relação aos profissionais quanto aos idosos. O tempo médio de aplicação da bateria foi de 48,7 min. Conclusões: A bateria DLOTCA-G é a primeira avaliação dinâmica dos componentes cognitivos de idosos disponível em português e mostrou ter boa aplicabilidade, não sendo identificadas dificuldades de aplicação por parte dos examinadores e nem dificuldades de compreensão por parte dos idosos.
\end{abstract}

Palavras-chave: Terapia Ocupacional, Idosos, Avaliação, Cognição.

\section{Cross-cultural adaptation of the DLOTCA-G (Dynamic Lowenstein Occupational Therapy Cognitive Assessment - for geriatric population) to Portuguese}

\begin{abstract}
Introduction: The DLOTCA-G battery (Dynamic Loewenstein Occupational Therapy Cognitive Assessment - for Geriatrics) is a dynamic assessment of the cognitive components of the elderly that evaluates eight areas: orientation, visual and spatial perception, praxis, visual motor construction, thinking operations, memory, and consciousness. Objective: To conduct a cross-cultural adaptation of the DLOTCA-G battery to the Portuguese language. Methods: The cross-cultural adaptation process was carried out through the following methodology:
\end{abstract}

Autor para correspondência: Márcia Maria Pires Camargo Novelli, Departamento de Gestão e Cuidados em Saúde, Universidade Federal de São Paulo, Campus Baixada Santista, Av. Silva Jardim, 136, Vila Mathias, CEP 11015-020, Santos, SP, Brasil, e-mail: mnovelli@uol.com.br; mnovelli@unifesp.br

Recebido em Nov. 1, 2013; 1ª Revisão em Jun. 2, 2014; Aceito em Jul. 9, 2014. 
translation; back translation; evaluation of semantic, idiomatic, cultural and conceptual equivalences; and pre-test.

Results: In the translation phase, some words were added or deleted in order to improve the understanding of the Portuguese version. In the evaluation of the semantic and idiomatic equivalence, 23 of the 355 items evaluated were discordant. None of the 37 items analyzed in the conceptual equivalence evaluation was discordant. Regarding cultural equivalence, two of the 37 items evaluated was discordant. The discordant items were modified from suggestions given by experts, generating the third translated and adapted version of the battery, which was used during the pre-test in a sample of 10 elderly persons of the community. In this phase, no difficulties were identified in its application, both for professionals and the elderly. The average time of the battery application was 48.7 minutes.

Conclusions: The DLOTCA-G battery is the first dynamic assessment of cognitive components in elderly people available in Portuguese, and it presents good applicability. No difficulties were identified in its implementation by the examiners or in its comprehension by the elderly people.

Keywords: Occupational Therapy, Elderly, Evaluation, Cognition.

\section{Introdução}

No Brasil, dados da contagem populacional de 2007 demonstram que, no período de 1997 a 2007, a populaçáo de pessoas de 60 anos ou mais cresceu $47,8 \%$ e, no grupo de idosos de 80 anos ou mais, 65\%, apresentando esses segmentos, assim, um crescimento superior ao crescimento de $21,6 \%$ da população brasileira total no mesmo período (INSTITUTO..., 2008).

O envelhecimento populacional brasileiro é uma realidade e nos remete a reflexôes sobre as condiçóes de saúde e a prevalência de morbidades nessa faixa etária da população.

A manutenção da cognição é um determinante crítico da qualidade de vida na velhice e na longevidade, como evidenciado pelos estudos de Seattle (SCHAIE, 1996 apud NERI, 2006), sendo o declínio cognitivo associado com desconforto pessoal, com perda de autonomia e com aumento dos custos sociais. Essas são razôes suficientes para que a pesquisa e a teorização sobre o assunto sejam das áreas mais fecundas da psicologia do envelhecimento (NERI, 2006).

Especificamente na área da Terapia Ocupacional, a avaliação dos aspectos cognitivos faz parte do raciocínio clínico do profissional (ROLEY et al., 2008; CARLETO et al., 2010) e se pauta na importância que esses aspectos têm para a manutenção da capacidade funcional/desempenho ocupacional dos indivíduos (GRIEVE; GNANASEKARAN, 2010).

A Associação Americana de Terapia Ocupacional, em seu último documento (ROLEY et al., 2008; CARLETO et al., 2010), identifica os aspectos do domínio profissional da Terapia Ocupacional e ilustra a inter-relação dinâmica entre eles. Todos os aspectos do domínio são de igual importância $e$, juntos, interagem para influenciar o engajamento do indivíduo nas ocupações e, consequentemente, na participação social e na sua saúde.
As habilidades cognitivas fazem parte das habilidades de desempenho que se inter-relacionam para a execuçấo das atividades/ocupaçôes. Essas habilidades envolvem a percepção sensorial, propriocepção, equilíbrio, estereognosia, relações espaciais, percepção de profundidade, memória, atenção, capacidade para resolução de problemas, entre outras.

São capacidades fundamentais para que as tarefas cotidianas sejam realizadas, já que nos permitem receber estímulos, processar as informaçóes e consequentemente produzir as respostas (CREPEAU, 2002; GRIEVE, 2006; GRIEVE; GNANASEKARAN, 2010).

A competência cognitiva é vista como um componente essencial para a independência e o desempenho na vida cotidiana dos indivíduos, principalmente de indivíduos idosos.

No dia a dia não realizamos tarefas de memória isoladamente das de raciocínio, de linguagem, de mobilidade ou de atenção. Todas as funçóes cognitivas são utilizadas em sincronia dentro de um contexto complexo (ambiente), a partir de uma intenção, com a finalidade de atingir determinados objetivos, como a realizaçáo das atividades de trabalho, atividades instrumentais e básicas da vida diária e de lazer (PARENTE, 2006).

Um estudo de revisão de instrumentos de avaliação cognitiva para idosos (DOUGLAS; LETTS; LIU, 2008) fez uma análise criteriosa dos instrumentos que são utilizados pelos terapeutas ocupacionais para avaliar os aspectos cognitivos. O estudo identificou 32 instrumentos e esses foram analisados considerando suas propriedades psicométricas (confiabilidade e validade) e concluiu que para uma avaliação breve da cognição o melhor instrumento é a versão modificada do Mini Exame do Estado Mental, seguido da versão original do Mini Exame do Estado Mental (MEEM). 
Para instrumentos que gastam mais de 30 minutos em sua aplicação, o estudo aponta que o Cognistat (MUELLER; KLERNAN; LANGSTON, 2001), o CASE (GENEAU; TAILLEFER, 1996) e o LOTCA-G (KATZ et al., 1995) são os instrumentos que apresentam as melhores propriedades psicométricas.

Ao entrar em contato com esses instrumentos, pelo estudo de suas características e itens, foi possível identificar que todos os três citados apresentam itens e/ou domínios de avaliação cognitiva similares aos instrumentos disponíveis em português, que comumente avaliam: orientação espacial e temporal, linguagem, atenção e concentração, capacidade visuoconstrutiva, habilidade visual, nomeação, fluência verbal, memória imediata e de evocação, como o Mini Exame do Estado Mental (FOLSTEIN et al., 1975; BRUCKI et al., 2003) ou o Exame Cognitivo de Addenbrooke - versão revisada (MIOSHI et al., 2006; CARVALHO; CARAMELLI, 2007), e que costumam ser utilizados na prática clínica e em pesquisas para a avaliação cognitiva de idosos.

Um diferencial apresentado pela bateria DLOTCA-G é que essa bateria propóe uma avaliação dinâmica dos componentes cognitivos na qual é possível identificar o potencial de aprendizado e as estratégias de pensamento a partir do uso de mediações durante a avaliação e inclui uma avaliação da consciência do indivíduo, de seus déficits cognitivos, que não está contemplada por nenhum dos instrumentos citados acima.

A avaliação dinâmica nos permite identificar a possibilidade de melhoria no desempenho do idoso a partir da interferência do terapeuta quando ele utiliza os níveis de mediação. Os níveis de mediação podem ser mediaçóes simples, que envolvem a alocação de recursos atencionais, ou mediaçôes mais complexas, em que há a interferência do terapeuta na tarefa, apontando o erro ou reduzindo as etapas da tarefa ou servindo de modelo de desempenho para o idoso (KATZ et al., 2012).

Através do uso da mediação é possível identificar qual estratégia é necessária para que o indivíduo consiga ter um melhor desempenho nas tarefas. Esse aspecto é de suma importância para se definirem estratégias de intervenção, a partir da implementação dessas estratégias de mediação, que habilitam o melhor desempenho, no contexto das intervençóes propostas aos idosos. O objetivo da avaliação dinâmica é medir como e em que medida o desempenho pode melhorar com orientação (HAYWOOD; LIDZ, 2007 apud KATZ et al., 2012).

Essa proposta de avaliação dinâmica dos aspectos cognitivos de idosos não é contemplada em nenhum dos instrumentos de avaliação cognitiva comumente utilizados na prática clínica e na pesquisa. Por esse motivo, o estudo de adaptação transcultural da bateria DLOTCA-G para o português do Brasil visa disponibilizar uma bateria de avaliação dos componentes cognitivos de idosos, ampliando o foco de entendimento de seu perfil cognitivo a partir da identificação e reconhecimento dos níveis de mediação necessários para o desempenho das tarefas.

\section{A bateria DLOTCA-G (Dynamic Loewenstein Occupational Therapy Cognitive Assessment - for Geriatric Population)}

A bateria DLOTCA-G (Dynamic Loewenstein Occupational Therapy Cognitive Assessment - for Geriatric Population) consiste de 25 subtestes divididos em oito áreas cognitivas: orientação, consciência, percepção visual, percepção espacial, práxis, construção visuomotora, operações de pensamento e memória. Por ser uma avaliação dinâmica, para cada subteste há uma pontuação dinâmica, estruturada em quatro ou cinco níveis de mediação para auxiliar no desempenho, além da pontuação estática que define o desempenho cognitivo do idoso variando de 1 a 4 pontos, sendo 1 = déficit severo e 4 = desempenho normal.

Os objetivos da avaliação dinâmica (KATZ et al., 2012) são:

- Identificar capacidades e incapacidades de cada indivíduo nas diferentes áreas;

- Mensurar o potencial de aprendizagem e reconhecer as estratégias de pensamento através do uso de uma avaliação dinâmica;

- Identificar o nível de consciência do sujeito para sua condição e incapacidade cognitiva.

A Figura 1 ilustra o processo de avaliação dinâmico proposto pela bateria DLOTCA-G.

A Tabela 1 ilustra os níveis de mediação utilizados na avaliação dinâmica.

A aplicação da bateria completa leva em torno de 45 minutos a 1h30, dependendo da quantidade de mediação necessária. Se o idoso for incapaz de completar a avaliação em uma única sessão, é possível aplicá-la em mais de uma sessão, sendo que a recomendação da dra. Noomi Katz é que sejam realizadas no máximo três sessōes de avaliação. 
Tabela 1. Níveis de mediação utilizados na bateria DLOTCA-G.

\begin{tabular}{lc}
\hline \multicolumn{1}{c}{ Nível de mediação } & Mediação \\
\hline 1. Intervenção geral & "Preste atenção." \\
2. Feedback geral & "Está exatamente igual?" \\
3. Feedback específico & "Aqui está o seu erro, tente novamente." \\
4. Feedback estruturado & O terapeuta inicia a atividade e o cliente continua. \\
5. Demanda reduzida & O terapeuta reduz as possibilidades da tarefa, realiza a atividade e o cliente refaz. \\
\hline
\end{tabular}

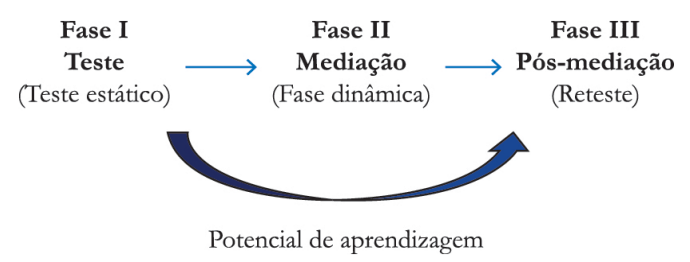

Figura 1. Ilustração do processo dinâmico utilizado na bateria DLOTCA-G.

Katz et al. (2012) apresentaram as primeiras análises das propriedades de medida da bateria DLOTCA-G (consistência interna e validade de constructo). O estudo foi realizado com 61 idosos com sequelas de acidente vascular encefálico e 52 idosos saudáveis. Os resultados, que variaram de 0,68 a 0,85 , exceto no domínio Memória, apontaram moderada a alta confiabilidade, pela consistência interna. Os valores obtidos foram: Percepção visual, 0,71; Percepção espacial, 0,85; Práxis, 0,79; Construçáo visuomotora, 0,83; Operaçóes de pensamento, 0,68; e Memória, 0,26. Segundo os autores, o domínio Memória apresentou baixa consistência interna por avaliar tipos de memória diferentes. Na validade de constructo, ambos os grupos foram comparados, considerando-se o desempenho antes e depois da mediação. $\mathrm{O}$ instrumento apresenta bons índices de confiabilidade interexaminador e bons índices de consistência interna para os diferentes domínios.

Considerando que no Brasil existe uma escassez de instrumentos formais e objetivos na área da Terapia Ocupacional, apontada por um estudo realizado por Chaves et al. (2010), a proposta do presente estudo é apresentar os dados relativos ao processo de tradução e adaptação transcultural da bateria DLOTCA-G para o português do Brasil.

\section{Diretrizes utilizadas no processo de adaptação transcultural}

Como diretrizes do processo de adaptação transcultural, este estudo utilizou a proposta de Guillemin et al. (1993), que prevê: a tradução, a retrotradução ou backtranslation, a avaliação das equivalências semânticas, idiomáticas, conceituais e culturais, realizada por um comitê de especialistas, e o pré-teste do instrumento traduzido e adaptado.

A tradução é uma etapa bastante complexa, realizada por dois tradutores independentes e cientes dos objetivos da tradução, que produzem duas versóes traduzidas do instrumento original que, ao serem comparadas, produzem a primeira versão traduzida (GIUSTI; BEFI-LOPES, 2008).

Após a primeira versão traduzida, é proposta a realização da retrotradução, que corresponde ao procedimento de retrotraduzir a versão do instrumento traduzido para a língua de origem, o que permite comparar a versão produzida com a versão original e identificar erros e discrepâncias na tradução, produzindo-se, então a segunda versão traduzida (GUILLEMIN et al., 1993).

A etapa seguinte pressupóe a análise das equivalências semânticas, idiomáticas, culturais e conceituais realizada por um comitê de juízes especialistas. Nessa etapa, as duas versôes (a original e segunda versão traduzida) são, então, comparadas. É importante que tal comparação identifique a equivalência nos diversos níveis e auxilie no processo de adaptação transcultural do instrumento a partir dessas análises. Devem fazer parte do comitê de juízes pesquisadores que tenham conhecimento sobre a área de saúde, de metodologia, de linguística e que tenham domínio dos idiomas envolvidos (BEATON et al., 2000).

Cabe ressaltar que a equivalência semântica representa a equivalência no significado das palavras quanto ao vocabulário e à gramática; a equivalência idiomática refere-se à equivalência de expressôes idiomáticas e coloquiais, que devem ser congruentes na cultura para a qual o instrumento está sendo traduzido; na equivalência experimental ou cultural, as situaçóes evocadas ou retratadas na versão original devem ser coerentes com o contexto cultural para o qual o instrumento será traduzido; e a equivalência conceitual refere-se à manutençáo do conceito proposto no instrumento original (GUILLEMIN et al., 1993). 
$\mathrm{Na}$ fase do pré-teste, utilizando-se a técnica da prova, o objetivo é verificar a compreensão do instrumento pela populaçáo-alvo; isso pode ser realizado por meio da aplicação do instrumento em uma amostra, sendo que, a cada questâo ou item, deve ser questionado ao entrevistado o que ele entendeu da questão, quais são suas dúvidas e sugestóes de possíveis significados equivalentes, caso necessário (GUILLEMIN et al., 1993).

\section{Materiais e métodos}

O estudo e o Termo de Consentimento Livre Esclarecido foram submetidos ao Comitê de Ética da Universidade Federal de São Paulo e foram aprovados sob número $0457 / 11$.

Foram traduzidos e adaptados transculturalmente o instrumento de avaliação e o manual de instruçôes da bateria DLOTCA-G. Ao longo de todo o processo de tradução da bateria e do manual foi mantido contato com a autora do instrumento - professora doutora Katz, que auxiliou no processo de adaptação transcultural respondendo aos questionamentos e autorizando e direcionando as mudanças propostas pela equipe a partir da adaptação da bateria para a língua portuguesa do Brasil.

$\mathrm{Na}$ etapa da tradução foram produzidas três versôes em português do instrumento original, a partir do trabalho de três equipes de pesquisadores, em que cada equipe teve um pesquisador responsável fluente em ambas as línguas: inglês (língua de origem do instrumento) e português. Cada uma das equipes foi composta por dois ou três pesquisadores.

As três versóes produzidas foram comparadas, item a item, e compiladas em uma única versão que originou a primeira versão em português da bateria DLOTCA-G, considerando o instrumento de avaliação e o manual de instruções.

No processo de retrotradução, um pesquisador cego aos objetivos do estudo e fluente em ambas as línguas (português e inglês), realizou a retrotradução da primeira versão em português para a língua de origem (inglês), processo que resultou na segunda versão traduzida da bateria.

Para o desenvolvimento da etapa de avaliação das equivalências semânticas, idiomáticas, culturais e conceituais foram convidados cinco especialistas da área de cognição e envelhecimento, sendo a equipe composta pelos seguintes juízes: professora doutora Eneida Mioshi, professora mestre Maria Conceição dos Santos, professora doutora Maria Teresa Carthery Goulart, professor doutor Paulo
Caramelli, professora doutora Vânia Aparecida Gurian Varoto.

Para a avaliação das equivalências foram construídos instrumentos de avaliação dessas equivalências, com uma pontuação que variou de $-1 \mathrm{a}+1$, sendo -1 = não equivale, 0 = indeciso $\mathrm{e}+1=$ equivale, para cada item avaliado. Quando os juízes pontuavam 0 ou -1 , foram orientados a sugerir modificações para esses itens. $\mathrm{Na}$ análise das respostas foram considerados como itens equivalentes e concordantes os itens que obtiveram $90 \%$ de concordância entre os juízes (ALEXANDRE; COLUCI, 2011), na pontuação +1 .

Quando os itens obtinham uma porcentagem inferior a $90 \%$ de concordância, as sugestôes oferecidas pelos juízes eram incorporadas e o item, modificado de acordo com essas sugestóes, visando a sua melhoria. Para os itens onde a concordância entre os juízes foi de $90 \%$ mas as sugestóes oferecidas foram pertinentes, elas foram incorporadas aos itens da bateria e ao manual de instruçōes, visando uma melhor adequação cultural.

Após a inclusão das sugestôes dos examinadores, tanto em relação ao instrumento como em relação ao manual de instruçôes, foi produzida a segunda versão traduzida e adaptada do instrumento e do manual de aplicação, para serem utilizados na fase do pré-teste.

A bateria DLOTCA-G contém um subteste, no domínio Memória, que precisa de adaptação transcultural para os locais onde a bateria é aplicada, pois o teste, que remete ao reconhecimento e nomeação de uma personalidade famosa $(\mathrm{PF})$, é realizado através da imagem/foto dessa personalidade.

Para a seleção da personalidade que compôs a versão brasileira foi realizado um pré-teste com 18 idosos saudáveis, oriundos do Centro de Convivência Vida Nova. Na versão original da bateria são apresentadas imagens de políticos ou governantes, o que, para a realidade brasileira, pode ser uma dificuldade, devido à grande heterogeneidade de escolaridade, que pode resultar no não reconhecimento e nomeação da personalidade (foco da avaliação), não por dificuldade cognitiva mas por simples desconhecimento. Foi proposto à autora do instrumento a possibilidade de trocar a categoria da personalidade famosa para atores, cantores, jogadores de futebol, considerando que essas figuras seriam de fácil reconhecimento e memorização para todos os níveis de escolaridade e camadas sociais do Brasil, o que foi prontamente aceito. Para a escolha dessa personalidade famosa as figuras selecionadas para o pré-teste foram: Hebe Camargo, Luís Inácio Lula da Silva (Lula), Edson 
Arantes do Nascimento (Pelé), Roberto Carlos e Sílvio Santos.

Os idosos foram entrevistados individualmente e as fotos dessas pessoas foram apresentadas uma após a outra. No momento da apresentação de cada foto foi questionado ao idoso: "Quem é a pessoa da foto?" e, em seguida, "Por que ela é conhecida?"

Para a realização do pré-teste do instrumento traduzido e adaptado foi estabelecida uma parceria com a Secretária de Assistência Social (SEAS) de Santos que autorizou a realização das avaliações no Centro de Convivência para a Terceira Idade Vida Nova.

$\mathrm{Na}$ fase do pré-teste, a segunda versão foi aplicada em uma amostra aleatória de 10 idosos saudáveis deste CECON. Os critérios de inclusão dos idosos foram: ter 60 anos ou mais, não apresentar distúrbios graves de linguagem, aceitar participar do estudo, assinar o Termo de Consentimento Livre e Esclarecido (TCLE), não apresentar doença psiquiátrica ou neurológica em atividade, não ter apresentado queixa de dificuldade cognitiva durante a anamnese e ter vida independente na comunidade. Essas informaçōes foram obtidas a partir de um checklist realizado no momento das entrevistas, visando a continuidade do processo de aplicação do pré-teste.

As avaliaçốes junto aos idosos foram realizadas no período de maio de 2011 a setembro de 2011 e todas foram realizadas em uma sala especialmente reservada para as avaliaçóes no Centro de Convivência Vida Nova, na cidade de Santos.

Os instrumentos de avaliação utilizados foram:

1. Identificação geral: Questionário semiestruturado onde foram colhidos dados das variáveis sociodemográficas dos idosos como idade, escolaridade, endereço, telefone de contato.

2. Bateria DLOTCA-G-segunda versão traduzida e adaptada.

Todas as dificuldades e observaçōes apresentadas pelos idosos e observadas pelos examinadores foram registradas, em um espaço reservado na folha de pontuação, com o objetivo de auxiliar nas modificaçôes necessárias para a finalização do processo de adaptação transcultural da bateria para o português do Brasil e em sua compreensibilidade.

Cabe ressaltar que se identificadas alteraçôes cognitivas nos idosos que participaram do estudo, o coordenador do centro de convivência deveria ser notificado para que o idoso fosse encaminhado para um serviço especializado.

\section{Resultados e discussão}

A bateria inteira foi traduzida para o português, considerando o manual de instruçóes e a folha de pontuação. A versão brasileira da bateria DLOTCA-G manteve o mesmo número de itens em comparação com a bateria original.

No processo de tradução foram feitas pequenas modificaçóes como inclusão e exclusão de palavras, visando à manutenção do sentido e do conteúdo das frases em português.

No processo de retrotradução, a primeira versão em português da bateria DLOTCA-G bem como do seu manual de instruçóes foram comparadas com o instrumento original: náo foram encontradas divergências entre as versôes.

$\mathrm{Na}$ avaliação das equivalências foram produzidos dois instrumentos de avaliação que contemplaram as avaliaçôes de equivalência semântica e idiomática e as avaliaçôes conceitual e cultural, respectivamente.

No instrumento de avaliação semântica e idiomática foram avaliados 355 itens, dos quais 23 apresentaram um índice de concordância inferior a $90 \%$. A média de concordância entre os examinadores foi de $92,28 \%$. A Tabela 2 apresenta os itens considerados discordantes e as sugestôes dos juízes incorporadas aos itens da bateria.

$\mathrm{Na}$ avaliação conceitual foram analisados 37 itens e nenhum dos itens apresentou índice de concordância inferior a $80 \%$, sendo a média de concordância entre os examinadores de $97,84 \%$.

$\mathrm{Na}$ avaliação cultural foram analisados 37 itens, dos quais dois itens apresentaram discordância. A média de concordância entre os examinadores foi de 94,59\%. A Tabela 3 apresenta os itens discordantes na avaliação da equivalência cultural e as sugestôes apresentadas pelos juízes e que foram incorporadas aos itens da bateria.

O mapeamento dessas análises e da incorporação das sugestôes feitas pelo comitê de especialistas resultou na produção da terceira versão traduzida e adaptada da bateria DLOTCA-G, a qual foi utilizada na fase do pré-teste do instrumento na população alvo da avaliação.

$\mathrm{Na}$ fase do pré-teste, 10 idosos do CECON fizeram parte da amostra. A Tabela 4 apresenta o perfil sociodemográfico desses idosos.

Os idosos que participaram do pré-teste eram, na grande maioria, do gênero feminino (90\%), com média de idade de 73 anos e média de escolaridade de 10 anos. 
Tabela 2. Itens discordantes na avaliação semântica e idiomática e as modificações sugeridas pelos examinadores.

\begin{tabular}{|c|c|c|}
\hline Tradução & $\begin{array}{l}\text { Sugestão do comitê de } \\
\text { especialistas }\end{array}$ & $\begin{array}{c}\text { Terceira versão traduzida e } \\
\text { adaptada }\end{array}$ \\
\hline $\begin{array}{l}8 \text { - Em alguns momentos eu vou } \\
\text { pedir para que você repita a tarefa } \\
\text { depois de mim, para que eu tenha a } \\
\text { certeza que você realmente sabe o } \\
\text { que fazer, então faça o melhor que } \\
\text { puder. }\end{array}$ & $\begin{array}{l}\text { Inclusão/exclusão/modificação } \\
\text { de palavras para facilitar a } \\
\text { compreensão da frase. }\end{array}$ & $\begin{array}{l}\text { Em alguns momentos eu vou } \\
\text { pedir para que você repita a tarefa } \\
\text { depois de mim, para que eu tenha a } \\
\text { certeza de que você realmente sabe } \\
\text { o que deve fazer, então faça da } \\
\text { melhor maneira possível. }\end{array}$ \\
\hline
\end{tabular}

14 - Ou antes de começar a avaliação?

26 - Você teve um derrame/uma lesão na cabeça?

30 - Quem é essa pessoa na foto?

33 - Mais tarde eu vou pedir que você lembre o nome do objeto e aponte onde eu o escondi.

36 - Memorize o nome dos objetos porque mais tarde eu vou perguntar a você quais objetos você viu anteriormente.

49 - Qual o nome dessa figura?

50 - Que tipo de figura é essa?

52 - Onde essa figura aparece?

54 - Que você faz com isso?

108 - Agora faça você mesmo.

130 - Dobre o papel de maneira que o envelope fechado pareça com uma carta sendo enviada.

138 - Agora eu vou pedir que você faça alguns gestos sem objetos, como se você estivesse utilizandoos numa representação.

166 - Vou te mostrar três cartas com figuras.
Inclusão/exclusão/modificação de palavras para facilitar a compreensão da frase.

Inclusão/exclusão/modificação de palavras para facilitar a compreensão da frase.

Inclusão/exclusão/modificação de palavras para facilitar a compreensão da frase.

Inclusão/exclusão/modificação de palavras para facilitar a compreensão da frase.

Inclusão/exclusão/modificação de palavras para facilitar a compreensão da frase.

Inclusão/exclusão/modificação de palavras para facilitar a compreensão da frase.

Inclusão/exclusão/modificação de palavras para facilitar a compreensão da frase.

Inclusão/exclusão/modificação de palavras para facilitar a compreensão da frase.

Inclusão/exclusão/modificação de palavras para facilitar a compreensão da frase.

Inclusão/exclusão/modificação de palavras para facilitar a compreensão da frase.

Inclusão/exclusão/modificação de palavras para facilitar a compreensão da frase.

Inclusão/exclusão/modificação de palavras para facilitar a compreensão da frase.

Inclusão/exclusão/modificação de palavras para facilitar a compreensão da frase.
Ou antes de vir para o setor de reabilitação/avaliação?

Você teve um derrame/um acidente na cabeça?

Diga-me quem é essa pessoa na foto.

Mais tarde eu vou pedir que você se lembre que objeto era e mostreme onde eu o escondi.

Memorize os objetos porque mais tarde eu vou lhe perguntar quais objetos você viu anteriormente.

Qual o nome dessa forma geométrica?

Que tipo de forma geométrica é essa?

Onde essa forma geométrica aparece?

O que você pode fazer com isso?

Agora faça você sozinho.

Dobre o papel de maneira que o envelope fechado se pareça com uma carta pronta para ser enviada.

Agora eu vou pedir que você faça alguns gestos sem objetos, como se você estivesse fazendo uma mímica utilizando-os numa representação.

Vou lhe mostrar três cartões com formas geométricas. 
Tabela 2. Continuação...

\begin{tabular}{lll}
\hline \multicolumn{1}{c}{ Tradução } & \multicolumn{1}{c}{$\begin{array}{c}\text { Sugestão do comitê de } \\
\text { especialistas }\end{array}$} & $\begin{array}{c}\text { Terceira versão traduzida e } \\
\text { adaptada }\end{array}$ \\
\hline $\begin{array}{l}182 \text { - Está igual ao do } \\
\text { desenho/figura? }\end{array}$ & $\begin{array}{l}\text { Inclusão/exclusão/modificação } \\
\text { de palavras para facilitar a } \\
\text { compreensão da frase. }\end{array}$ & $\begin{array}{l}\text { O seu está igual ao do desenho/ } \\
\text { figura? }\end{array}$ \\
\hline
\end{tabular}

\section{3 - Aqui está o seu erro, faça} novamente.

186 - Eu vou te mostrar como construir o modelo.

189 - Ele deve ser idêntico em tamanho e posição ao desenho.

\section{2 - Você errou aqui.}

220 - Observe e depois que eu terminar você faz igual.

225 - Ambos os ponteiros deveriam ter o mesmo comprimento?

285 - Diga-me se você os viu previamente ou não.

352 - O principal significado é que o nível de mediação mais frequente fornece indicações para o planejamento da intervenção.
Alteração da palavra erro.

Inclusão/exclusão/modificação de palavras para facilitar a compreensão da frase.

Modificação na estrutura da frase para facilitar a sua compreensão.

Modificação na estrutura da frase para facilitar o entendimento.

Inclusão/exclusão/modificação de palavras para facilitar a compreensão da frase.

Modificação na estrutura da frase para facilitar a sua compreensão.

Modificação na estrutura da frase para facilitar a sua compreensão.

Modificação na estrutura da frase para facilitar a sua compreensão.
Mantivemos a palavra erro.

Eu vou lhe mostrar como construir o modelo.

Ele deve ser idêntico ao desenho em tamanho e posição.

Aqui está o seu erro.

Observe e, quando eu terminar, você faz igual.

Os dois ponteiros deveriam ter $\mathrm{o}$ mesmo comprimento?

Diga-me se eu lhe mostrei previamente ou não.

Entretanto, o significado é principalmente que o nível de mediação mais frequente fornece indicações para o planejamento da intervenção.

Tabela 3. Itens discordantes na avaliação de equivalência cultural.

\begin{tabular}{lll}
\hline \multicolumn{1}{c}{ Item/tradução } & \multicolumn{1}{c}{ Sugestão } & $\begin{array}{c}\text { Terceira versão traduzida e } \\
\text { adaptada }\end{array}$ \\
\hline Personalidade famosa & $\begin{array}{l}\text { Selecionar uma pessoa conhecida } \\
\text { no Brasil. }\end{array}$ & Roberto Carlos \\
Em que estação do ano nós estamos? & $\begin{array}{l}\text { Modificar a questão, pois } \\
\text { não é cultural a utilização da } \\
\text { identificação do tempo pelas } \\
\text { estações do ano no Brasil. }\end{array}$ & Que dia do mês é hoje? \\
\hline
\end{tabular}

Tabela 4. Perfil sociodemográfico dos idosos da amostra no pré-teste.

\begin{tabular}{lc}
\hline Variáveis sociodemográficas & Idoso $(\mathrm{n}=10)$ \\
\hline Idade & $73,40^{\mathrm{a}} \pm 5,71^{\mathrm{b}}$ \\
Escolaridade & $10,20^{\mathrm{a}} \pm 4,21^{\mathrm{b}}$ \\
Gênero & Fem $-90 \%$ \\
& Masc $-10 \%$ \\
\hline
\end{tabular}

${ }^{a}$ Médias. ${ }^{b}$ Desvios-padrão.

$\mathrm{Na}$ fase do pré-teste, a aplicação da bateria em idosos saudáveis teve o objetivo de explorar, sob diversas perspectivas, o desempenho dos idosos, avaliar a sua compreensão sobre o que lhes era dito e verificar se a versão traduzida estava em uma linguagem compreensível.

Em relação à compreensão da bateria foi possível constatar que não houve problemas durante a sua aplicação. Os pesquisadores não encontraram dificuldades na sua aplicação e os idosos compreenderam as tarefas e as orientaçôes, demonstrando que a versão produzida e adaptada para a língua portuguesa do Brasil está adequada.

$\mathrm{Na}$ fase de seleção da personalidade famosa, todas as imagens apresentadas obtiveram 100\% de reconhecimento, mas não de nomeação. Duas personalidades famosas foram reconhecidas por seu 
apelido e, embora reconhecidas, os idosos ficavam em dúvida em relação ao nome completo. Foi considerado, além do reconhecimento, a nomeaçáo e o tempo para a conclusão dessas duas etapas; a imagem que obteve $100 \%$ de reconhecimento e nomeação no menor tempo foi a do cantor Roberto Carlos, a qual foi incorporada ao subteste Personalidade famosa (PF) no domínio de Memória.

O tempo de aplicação da bateria completa foi em média de 48,7 minutos \pm 10 .

\section{Considerações finais}

O processo de tradução e adaptação transcultural de um instrumento é uma tarefa complexa e deve seguir uma metodologia rigorosa que vai além da simples traduçáo, levando em conta aspectos culturais e de linguagem, que devem ser considerados sempre que um novo instrumento é traduzido para outra língua.

A partir dos resultados obtidos pelo processo de adaptação transcultural da bateria DLOTCA-G, está disponível, em português do Brasil, a primeira avaliação dinâmica dos componentes cognitivos de idosos, que seguirá em estudo para a avaliação das suas propriedades psicométricas. Cabe ressaltar que o sistema estruturado e dinâmico da mediação é útil para se obterem informaçôes que não seriam obtidas por meio de instrumentos tradicionais (do tipo estático). Tais informaçóes não se limitam a identificar e quantificar os déficits, mas também orientam sobre o tipo e a quantidade de ajuda que são essenciais para que o sujeito possa melhorar seu desempenho nas tarefas que realiza.

\section{Referências}

ALEXANDRE, N. M. C.; COLUCI, M. Z. O. Validade de conteúdo nos processos de construção e adaptação de instrumentos de medidas. Ciência \& Saúde Coletiva, Rio de Janeiro, v. 16, n. 7, p. 3061-3068, 2011. http:// dx.doi.org/10.1590/S1413-81232011000800006. PMid:21808894

BEATON, D. E. et al. Guidelines for the process of cross-cultural adaptation of self-report measures. Spine, Stanford, v. 25, n. 24, p. 3186-3191, 2000. http:// dx.doi.org/10.1097/00007632-200012150-00014. PMid:11124735

BRUCKI, S. M. et al. Sugestôes para uso do mini-exame do estado mental no Brasil. Arquivos de Neuro-Psiquiatria, São Paulo, v. 61, n. 3, p. 777-781, 2003. http:// dx.doi.org/10.1590/S0004-282X2003000500014.

CARLETO, D. G. S. et al. Estrutura da prática da Terapia Ocupacional: domínio e processo. Revista Triângulo, Uberaba, v. 3, n. 2, p. 57-147, 2010.
CARVALHO, V. A.; CARAMELLI, P. Brazilian adaptation of the Addenbrooke's Cognitive Examination-Revised. Dementia \& Neuropsychologia, São Paulo, v. 1, n. 2, p. 212-216, 2007.

CHAVES, G. F. S. et al. Escalas de avaliação para Terapia Ocupacional no Brasil. Revista de Terapia Ocupacional da Universidade de São Paulo, São Paulo, v. 21, n. 3, p. 240-246, 2010.

CREPEAU, E. B. Análise de Atividades: uma forma de refletir sobre desempenho ocupacional. In: NEISTADT, M. E.; CREPEAU. E. B. Terapia Ocupacional. Rio de Janeiro: Guanabara Koogan, 2002. p. 121-133.

DOUGLAS, A.; LETTS, L.; LIU, L. Review of cognitive assessments for older adults. Physical \& Occupational Therapy in Geriatrics, London, v. 26, n. 4, p. 13-43, 2008. http://dx.doi.org/10.1080/02703180801963758.

FOLSTEIN, M. F.; FOLSTEIN, S. E.; MCHUGH, P. R. "Mini-mental state": a practical method for grading the cognitive state of patients for the clinician. Journal of Psychiatric Research, Great Britain, v. 12, n. 3, p. 189-198, 1975. http://dx.doi.org/10.1016/00223956(75)90026-6. PMid:1202204

GENEAU, D.; TAILLEFER, D. Cognitive Assessment Scale for the Elderly (CASE). Montréal: SEPEC, 1996. Disponível em: <http://www.sepec.ca/case.html>. Acesso em: 10 fev. 2010.

GIUSTI, E.; BEFI-LOPES, M. D. Tradução e adaptação transcultural de instrumentos estrangeiros para o Português Brasileiro (PB). Pró-Fono Revista de Atualização Cientifica, Barueri, v. 20, n. 3, p. 207-210, 2008. http:// dx.doi.org/10.1590/S0104-56872008000300012. PMid:18852970

GRIEVE, J. Neuropsicologia em Terapia Ocupacional: exame da percepção e cognição. Sáo Paulo: Santos, 2006.

GRIEVE, J.; GNANASEKARAN, L. Neuropsicologia para Terapeutas Ocupacionais: cogniçáo no desempenho ocupacional. São Paulo: Santos, 2010.

GUILLEMIN, F.; BOMBARDIER, C.; BEATON, D. E. Cross-cultural adaptation of health-related quality of measures: literature review and proposed guidelines. Journal of Clinical Epidemiology, Great Britain, v. 46, n. 12, p. 1417-1432,1993.

INSTITUTO BRASILEIRO DE GEOGRAFIA E ESTATÍSTICA - IBGE. Contagem da população 2007. Rio de Janeiro: IBGE, 2008. Disponível em: <http:// www.ibge.gov.br/home/estatistica/populacao/contagem2007/>. Acesso em: 10 fev. 2010.

KATZ, N.; AVERBUCH, S.; BAR-HAIM EREZ, A. Dynamic Lowenstein Occupational Therapy Cognitive Assessment-Geriatric Version (DLOTCA-G): assessing change in cognitive performance. The American Journal of Occupational Therapy, London, v. 66, n. 3, p. 311-319, 2012. http://dx.doi.org/10.5014/ajot.2012.002485. PMid:22549596 
KATZ, N.; ELAZAR, B.; ITZKOVICH, M. Construct validity of a geriatric version of the Loewenstein Occupational Therapy Cognitive Assessment (LOTCA) battery. Physical \& Occupational Therapy in Geriatrics, Bethesda, v. 13, n. 3, p. 31-46, 1995. http://dx.doi.org/10.1080/ J148v13n03_03.

MIOSHI, E. et al. The Addenbrooke's Cognitive Examination Revised (ACE-R): a brief cognitive test battery for dementia screening. International Journal of Geriatric Psychiatry, Manchester, v. 21, n. 1, p. 78-85, 2006.

MUELLER, J.; KIERNAN, R.; LANGSTON, J. W. Manual for cognistat: the neurobehavioral cognitive sta- tus examination. Fairfax: The Northern California Neurobehavioral Group, 2001.

NERI, A. L. Envelhecimento cognitivo. In: FREITAS, E. V. et al. Tratado de Geriatria e Gerontologia. Rio de Janeiro: Guanabara Koogan, 2006. p. 1236-1244.

PARENTE, M. A. M. P. Cognição e envelhecimento. Porto Alegre: Artmed, 2006.

ROLEY, S. S. et al. Occupational therapy practice framework: domain \& practice, 2 nd edition. The American Journal of Occupational Therapy, Bethesda, v. 62, n. 6, p. 625-683, 2008. http://dx.doi.org/10.5014/ ajot.62.6.625. PMid:19024744

\section{Contribuição dos Autores}

Marcia Novelli: responsável pelo desenho do estudo, condução, coleta e análise dos dados e escrita do artigo. Nataly Marques: coleta, análise dos dados e escrita do artigo. Mariana Matteuci, Amanda Sardinha, Juliana Kuga e Amanda Fabrício: tradução do material. Renata Mendes e Lúcia Uchôa: tradução do material e escrita do artigo. Noomi Katz: suporte contínuo na tradução e adaptação transcultural da bateria para o português. Todos os autores aprovaram a versão final do texto. 